MEMORIAL TABLET TO LORD LISTER.

$A$ TABLET in memory of the late Lord Lister was unveiled by Lord Rayleigh at King's College, London, on January i4. The unveiling was preceded by an impressive ceremony in the chapel, among those present being Dr. Herringham (Vice-Chancellor of the University), Sir Rickman Godlee (president of the Royal College of Surgeons), Sir William Crookes (president of the Royal Society), Sir Henry Miers (principal of the University), Dr. Caldecott (Dean of King's College), Sir St. Clair Thomson, Prof. Halliburton, Prof. J. M. Thomson, Sir David Ferrier, Sir John Rose Bradford, and Mr. and Mrs. J. J. Lister.

Lord Rayleigh expressed his pleasure at thus being able to pay a small tribute to the memory of Lister, under whom he had been privileged to serve for a time at the Royal Society. It is now a commonplace that by his advances in surgery he had saved more lives than Napoleon had destroyed. Lister, in addition to his extreme modesty, was always ready to acknowledge obligations, and delighted his French colleagues by his generous insistence that his work was a natural development of that of Pasteur.

Lord Rayleigh was followed by the Vice-Chancellor of the University, Dr. Herringham, who pointed out that Lord Lister, at the invitation of King's College Hospital, gave up the chair he held at Edinburgh. Dr. Herringham expressed the wish that such translations were more common, for they conferred honour not only on those translated, but also on the institutions from which they emanated.

Sir Henry Miers, Prof. Halliburton, and Dr. Caldecott also spoke briefly.

The tablet, which has been erected in the corridor outside the chapel, bears the inscription :- -

"In affectionate and respectful memory of Joseph, Baron Lister, F.R.S., O.M., Professor of Clinical Surgery in King's College from $1877-1892$, and for many years consulting surgeon to the King's College Hospital, Member of the Council and Life Governor of the College, this tablet is erected. His name will be handed down to posterity as the founder of antiseptic surgery, one of the greatest discoveries in history and a source of inestimable benefit to mankind."

\section{THE "DAVON" MICRO-TELESCOPE.}

MESSRS. DAVIDSON AND CO. have recently I produced a "micro-telescope," an instrument which is essentially a microscope of ordinary construction carrying a short focus telescope objective and tube below the stage. It may here be remarked that the ordinary terrestrial telescope with erecting eyepiece is nothing more than an object-glass, and a microscope, for an erecting eyepiece is nothing more than a microscope of low power. This is at times of great use in the workshop or laboratory, where a lowpower reading microscope may be wanted in a hurry, but it is not everyone who remembers that a pocket telescope contains within itself this instrument also. While, therefore, the micro-telescope and the ordinary telescope with erecting eyepiece have the same sequence and function of lenses, and each gives an erect image, yet in proportions and practically the micro-telescope is a very different thing. The triple objective in the micro-telescope, though of only $5 \frac{1}{2}$ in. focal length, instead of the usual 8 or 9 in., successfully withstood the following severe test. At a distance of a rod, pole, or perch and a half, and a yard and a quarter (which works out as 342 in.), a Bellows French Dictionary coull be read perfectly and with a $\frac{2}{3}$ in. microscope objective a circle of NO. 2308 , VOL. 92$]$
$3 \frac{1}{8}$ in. in diameter could be seen at once all in focus and with no sign of colour. As a more severe test a number of groups of artificial double stars, made by small needle-holes in tin foil, of which the closest group were all separated by I/IOo in. centre to centre, were set up at the same distance, and all were clearly double stars as seen in the micro-telescope, clear, sharp, and without colour, but with the first diffraction ring clearly showing. These stars subtended centre to centre an angle of almost exactly $6^{\prime \prime}$ of arc, and as the needle-holes were not geometrical points, this test shows that the objectglass was up to the optical limit imposed by the size of the wave-length of light.

Some crumbs were then placed on the floor at a distance of four yards, and strongly illuminated, and the microscope with a $I$ in. object-glass focussed on the crumbs. Presently some mice came out, and made themselves at home with the crumbs. The mice could be examined at this distance without their being aware of it so well that individual hairs were easily visible and about half a mouse was in the field of view. In point of size it appeared about the same as a beaver within a foot or two. The magnifying power was measured and found to be 42 .

A plane mirror silvered on the front face is provided to be clipped on in front of the telescope objective, so that objects may be examined without tilting the micro-telescope to an inconvenient angle. This has the two motions necessary to bring an object into the field of view. The double-star test showed that the mirror interfered slightly with the perfection of the image, but not to such an extent as to be noticeable except with so severe a test. A more serious difficulty, however, is that of finding an object when seen in this way. It would be easy enough with the moon, for instance, and perhaps with a bright planet like Venus or Jupiter, but it would probably require some practice to find such a star as $\beta$ Cygni.

A further attachment is provided by means of which the microscope tube is replaced by a camera so that either microscope photographs may be obtained if the telescope element is replaced by a substage illuminator, or if the telescope fitting is in its place the combination enables telephotographs to be taken; some of these submitted by the makers show that in this domain also excellent results are possible.

Altogether the new instrument is one with many possibilities, and it will appeal to people with widely different interests.

C. V. Boys.

\section{A NEW INCANDESCENT ELECTRIC} LAMP.

A NEW incandescent electric lamp with an efficiency of about 0.5 watt per candle-power has just been placed on the market by several of the leading manufacturers in this country. It is only a few years since the tungsten filament lamp, with an efficiency of between $x$ and $1 \frac{1}{4}$ watts per candle-power appeared, to displace the carbon filament lamp the efficiency of which was between 3 and 4 watts per candle-power. In the case of the "half-watt" lamp, however, there is no change in the material of the filament. This is still tungsten.

Hitherto the tungsten lamp has been run at a temperature of about $2100^{\circ} \mathrm{C}$., for although this is roughly $800^{\circ} \mathrm{C}$. below the melting point of the metal, an effort to obtain a higher efficiency by employing a higher working temperature produced a deposit of metallic tungsten on the bulb. Analysis of the residual gases left in the bulb after exhaustion showed that the only one which could cause this effect was water 